\title{
Danos causados por medicamentos: responsabilidade civil do produtor no âmbito da legislação portuguesa
}

Damage caused by medical drug: producer liability under Portuguese law

Daño causado por medicamentos: responsabilidad del productor según la ley portuguesa

Mickael Martins ${ }^{1}$

\section{Resumo}

Objetivo: analisar, por um lado, o regime jurídico aplicável em caso de danos causados por medicamentos e, por outro lado, as dificuldades que se erigem com as (in)suficiências desse mesmo regime. Metodologia: foi realizada análise bibliográfica sobre este tema. Resultados: muito embora o regime legal em vigor se revele adequado à generalidade dos produtos, não se pode afirmar o mesmo em relação a alguns aspetos de regime quando em causa esteja um produto-medicamento, atentas as suas características próprias e a interação com o corpo humano que de imediato se estabelece. Conclusão: à imagem do que sucedeu em outros ordenamentos jurídicos europeus, poderia equacionar-se legislar especificamente sobre a responsabilidade civil decorrente de danos causados por medicamentos, como é o caso da Alemanha, ou consagrar algumas diferenças de regime quando em causa esteja um medicamento, como sucedeu em Espanha.

Palavras-chave: Preparações farmacêuticas. Responsabilidade civil. Segurança de produtos para o consumidor.

\begin{abstract}
Objective: to analyze, on the one hand, the legal regime applicable in case of damages caused by medicines and, on the other hand, the difficulties that arise with the (in) sufficiencies of that same regime. Methodology: a bibliographic analysis was carried out on this topic. Results: although the legal regime in force proves to be adequate to most products, the same cannot be said when a medicine is concerned, taking into account its own characteristics and the interaction with the human body that immediately establishes itself. Conclusion: as in other European legal systems, it could be envisaged to legislate specifically on civil liability arising from damage caused by drugs, as is the case in Germany, or to enshrine some regime differences when a drug is concerned, as happened in Spain.
\end{abstract}

Keywords: Pharmaceutical preparations. Civil liability. Product safety for the consumer.

\section{Resumen}

Objetivo: analizar, por un lado, el régimen legal aplicable en caso de daños causados por medicamentos $y$, por otro lado, las dificultades que surgen con la (in)suficiencia de ese mismo régimen. Metodología: se realizó un análisis bibliográfico sobre este tema. Resultados: aunque el régimen legal vigente resulta adecuado para la mayoría de los productos, no se puede decir lo mismo cuando se trata de un medicamento, teniendo en cuenta sus características propias y la interacción con el cuerpo humano que se establece de inmediato. Conclusión: como fue el caso en otros sistemas legales europeos, podría

\footnotetext{
${ }_{1}^{1}$ Mestre em Direito pela Faculdade de Direito da Universidade de Coimbra, Portugal; investigador do Centro de Direito Biomédico, Coimbra, Portugal. https://orcid.org/0000-0002-0216-9649. E-mail: mickaelmartins94@hotmail.com.
} 
preverse legislar específicamente sobre la responsabilidad civil derivada del daño causado por los medicamentos, como es el caso en Alemania, o consagrar algunas diferencias de régimen cuando se trata de uno medicamento, como sucedió en España.

Palabras clave: Preparaciones farmacêuticas. Responsabilidad civil. Seguridad del produto para el consumidor.

\section{Introdução}

\section{Caso Stalinon}

Medicamento colocado no mercado em 1953, em França, indicado para o tratamento da furunculose e certas doenças de pele, responsável pela morte de 102 pessoas em virtude da neurotoxidade do produto.

\section{Caso Talidomida}

Também conhecido como caso Contergan, esse fármaco começou a ser comercializado na Europa a partir de 1956, inicialmente como sedativo, anti-inflamatório e hipnótico e, posteriormente, iniciou-se a sua utilização durante o período de gravidez como forma de controlar as náuseas sentidas pelas gestantes. Nessa senda, só na Alemanha, país onde foi fabricado, mais de quatro mil bebés nasceram com malformações físicas ou ausência total de membros.

\section{Caso MER-29}

Medicamento destinado ao tratamento do colesterol, introduzido no mercado estadunidense em 1960, e que acabaria por ser retirado logo em 1962, em virtude de ter provocado graves reações adversas a mais de cinco mil pessoas, nomeadamente a formação de cataratas e cegueira.

\section{Caso Dietilestilbestrol (DES)}

Medicamento colocado no mercado dos Estados-Unidos da América (EUA) na década de 40 do século passado - e também comercializado na Europa -, o qual passou a ser utilizado sobretudo a partir de 1948 com o objetivo de prevenir o aborto espontâneo. Só em 1971, com a publicação de um estudo de caso-controlo elaborado por HERBST (1), é que se estabeleceu a relação causal entre a toma do fármaco e os seus efeitos nocivos, concretamente, o desenvolvimento de adenocarcinoma vaginal nas filhas das mulheres que tomaram esse medicamento, expostas ao mesmo in utero. 


\section{Caso Mohrange}

Data de 1972, quando mais de duas centenas de crianças foram intoxicadas por esse talco, tendo a grande maioria falecido - em causa estava um defeito de fabrico, dado que o talco continha mais de $6 \%$ de hexaclorofeno, tornando-se tóxico.

\section{Caso Mediator}

Em causa está um medicamento indicado para o tratamento da diabetes, mas igualmente utilizado no controlo de apetite, ao qual se associou o surgimento de patologias cardíacas, afetando as válvulas e impedindo o seu correto funcionamento, sendo que este fármaco foi responsável pela morte de 500 pessoas em França e cerca de 3.500 pessoas foram hospitalizadas por complicações relacionadas com o mesmo.

A segurança dos medicamentos não é absoluta - nem se exige que assim o seja. Determinante é que aqueles, a fim de serem comercializados pelos laboratórios farmacêuticos, apresentem uma relação benefício-risco positiva/favorável, isto é, que os benefícios advenientes do consumo de um medicamento superem os potenciais riscos que o mesmo possa desencadear (2). A fim de aferir da qualidade, segurança e eficácia terapêutica de um determinado medicamento, o mesmo é submetido a ensaios pré-clínicos - mediante a realização de ensaios de laboratório e em animais - e clínicos, destinados à análise do metabolismo do fármaco e a conhecer os efeitos farmacológicos e farmacodinâmicos, nomeadamente, os riscos e efeitos secundários mais relevantes. Com base nos resultados obtidos nessa fase de experimentação, o laboratório produtor requer ao Autoridade Nacional do Medicamento e Produtos de Saúde (Infarmed), Instituto Público (IP) de Portugal, a concessão de uma autorização de introdução no mercado (AIM), de que depende, salvo disposição em contrário, a comercialização de medicamentos no território nacional. (3)

Não obstante, os casos com que iniciámos o presente texto são a evidência fáctica de que a avaliação e monitorização da qualidade, segurança e eficácia terapêuticas não se podem limitar aos ensaios clínicos prévios à concessão de uma AIM e, portanto, prévias à comercialização dos medicamentos. Por um lado, porque - sobretudo por força do desastre da talidomida - são hoje evidentes as demais limitações próprias de um ensaio clínico, a exigirem a instituição de sistemas de farmacovigilância, com vista à vigilância constante dos medicamentos, que tiveram como projeto-piloto de monitorização internacional o Programa Internacional de Monitorização de Reações Adversas, coordenado pela Organização Mundial 
de Saúde (OMS), em 1968 (4). Por outro lado, porque, já depois de introduzido no mercado, pode muito bem suceder que o fármaco revele determinados riscos de reações adversas que não foram possíveis detetar aquando da sua introdução no mercado, atento o estado dos conhecimentos científicos e técnicos, também eles a exigirem uma resposta célere daqueles sistemas e a evidenciarem a necessidade de monitorização constante dos medicamentos e a imporem, v.g., sobre o laboratório produtor, após a concessão de autorização, o dever de adoção e de manutenção de um sistema de farmacovigilância, dispondo, nomeadamente, de modo permanente e contínuo, de uma pessoa responsável pela farmacovigilância - para além da elaboração de relatórios periódicos de segurança e da realização de estudos de segurança pós-autorização, como veremos.

Ao Infarmed, enquanto entidade responsável pelo acompanhamento, coordenação e aplicação do Sistema Nacional de Farmacovigilância, incumbe a adoção de todas as medidas necessárias para a notificação de reações adversas por parte de todos aqueles que integram a estrutura daquele sistema, v.g., pela promoção de formação na área da farmacovigilância. Ainda que existam várias metodologias, a principal - e que constitui o método mais relevante de monitorização de reações adversas - ocorre por via da notificação espontânea (5) (6) (7). Sucede que, embora essa tendência se tenha vindo a alterar paulatinamente, é transversal aos vários sistemas nacionais o baixo número de notificações espontâneas, por múltiplos fatores, estimando-se que apenas uma percentagem reduzidíssima da suspeita de reações adversas seja efetivamente comunicada às entidades responsáveis em cada país. É com base nessa factualidade que se tem procurado agilizar o ato de notificar, sobretudo através do recurso e da implementação da tecnologia nesse domínio, seja, por exemplo, pela informatização desse procedimento e pela implementação, entre nós, do Portal de Notificação de Reações Adversas, seja, v.g., pelo desenvolvimento de novas aplicações para smartphone - é o caso da VigiBip, desenvolvida em França pela Universidade de Toulouse -, colocando à distância de um clique a notificação de uma suspeita de reação adversa.

Mas ainda assim, mesmo com todos estes progressos em ordem à salvaguarda da saúde pública e, em particular, daqueles que tomam determinado fármaco, pode muito bem suceder que este não apresente a segurança com que legitimamente se pode contar. Quer isto dizer que pode advir a uma pessoa uma reação nociva e não intencional a um medicamento e cuja natureza, gravidade, intensidade ou consequências sejam incompatíveis com os dados constantes do resumo das características do medicamento (RCM) - são essas reações 
adversas graves e inesperadas que poderão desencadear a eventual responsabilização do laboratório produtor, porquanto, por um lado, as reações adversas que tenham sido detetadas no âmbito dos ensaios pré-clínicos e clínicos - tradicionalmente designadas de efeitos secundários - integram o RCM e, portanto, derivam da conclusão de que os benefícios concedidos pelo medicamento em questão superam os potenciais riscos associados ao mesmo, sem que se possa falar de defeito do medicamento e, por outro lado, porque aquelas reações adversas graves e inesperadas, porque não previstas, não foram consideradas na avaliação da relação benefício-risco do medicamento, podendo chegar-se à conclusão que a mesma é desfavorável e, em consequência, ser tal circunstancialismo subsumível no regime da responsabilidade decorrente de produtos defeituosos (8).

Esse regime - que não prejudica, nem afasta, o eventual recurso às regras gerais da responsabilidade civil, contratual ou extracontratual, surgindo como um acréscimo de proteção da pessoa lesada - encontra-se previsto no Decreto-Lei $n .{ }^{\circ} 383 / 89$, de 06 de Novembro (8), atualmente com a redação dada pelo Decreto-Lei n. ${ }^{\circ}$ 131/2001, de 24 de Abril, que procedeu à transposição, para o ordenamento jurídico português, da Diretiva n.. 85/374/CEE, de 25 de Julho de 1985 (9), relativa à aproximação das disposições legislativas, regulamentares e administrativas dos Estados-membros em matéria da responsabilidade decorrente de produtos defeituosos, e consagra a responsabilidade objetiva do produtor pelos danos causados por defeitos dos produtos que põe em circulação (artigo 1.ำ). Essa Diretiva surgiu como resposta às modificações ocorridas no âmbito dos processos de produção, nomeadamente, através da sua automatização, da produção em série e da distribuição em cadeia dos produtos (10), que puseram em evidência a inadequação das regras tradicionais em ordem à tutela eficaz da pessoa lesada em virtude de um dano causado por um determinado produto - mormente por força do ónus da prova da culpa que impende sobre esta última.

\section{Da responsabilidade civil decorrente de produtos defeituosos}

Pelo advento da industrialização dos processos de produção surgiram novos produtos, aperfeiçoaram-se outros tantos e, sobretudo, tornou-se possível a produção em série, abrangendo um cada vez maior número de pessoas, sendo inegável a melhoria qualitativa de vida que a proliferação de determinados produtos trouxe para a coeva sociedade do século XX.

Não obstante, por via de todas essas inovações, alcançáveis através da automatização do processo produtivo, com a introdução de máquinas complexas e sofisticadas, as quais, as 
mais das vezes, procedem à substituição total da mão-de-obra humana - com o revés de exponenciarem a verificação de acidentes generalizados e inevitáveis. A produção em série com a padronização dos produtos e a sua multiplicação, conduzindo a um aumento de produtividade e da distribuição em cadeia, passando o produtor a dedicar-se em exclusivo ao fabrico do seu produto -, erigiu entre este e o consumidor final uma cadeia por vezes longa de transmissão (10), com a consequência de se verificar uma não coincidência entre aquele e a pessoa do vendedor, por um lado, mas também uma não coincidência entre o adquirente do produto e o seu efetivo consumidor ou utilizador. Desvirtuou-se, assim, a tradicional relação que se estabelecia entre produtor e consumidor, respetivamente parte e contraparte da relação jurídica de compra e venda, - globalmente considerados como os "verdadeiros pressupostos económicos e dados materiais ou infraestruturais da responsabilidade civil do produtor" (10) - e verificou-se, simultaneamente, um aumento exponencial dos acidentes de consumo (10), porquanto o fenómeno da produção em massa encontra necessariamente, como seu correspetivo, o consumo de massas, erigindo-se o problema dos danos causados por produtos defeituosos como um problema social a que urgiu dar uma resposta cabal por parte dos vários ordenamentos jurídicos.

Naturalmente que sempre se poderá arguir existirem já, ao tempo de todas estas alterações no âmbito dos processos de produção, mecanismos tendentes à reparação do dano causado por um determinado produto defeituoso, quais sejam o da responsabilidade contratual ou o da responsabilidade extracontratual. Sucede que as profundas modificações operadas evidenciaram a inadequação do direito tradicional para assegurar uma idónea proteção da pessoa lesada.

Por um lado, o regime constante do Código Civil português (11), nos seus artigos 913.ำ e seguintes (sob a epígrafe venda de coisas defeituosas), não tutela diretamente a relação produtor-consumidor porquanto, como vimos, o advento da distribuição em cadeia teve como consequência o afastamento do primeiro em relação ao segundo, levando a que o consumidor não possa fazer valer os seus direitos diretamente contra o produtor por essa via - atenta a relatividade dos contratos e a sua eficácia inter partes -, apenas podendo fazê-lo contra o vendedor do produto em questão e, além disso, essa disciplina legislativa não é aplicável a consumidores não adquirentes, simples utentes ou bystanders - todos eles potenciais lesados. É muito frequente, nomeadamente no que aos medicamentos diz respeito, a pessoa lesada em 
virtude da toma de um medicamento defeituoso, não corresponder à pessoa que adquiriu o respetivo fármaco, não tutelando eficazmente a sua posição.

Por outro lado, no que concerne à responsabilidade civil extracontratual de direito comum, agigantam-se as dificuldades de prova, especialmente no que concerne ao ónus da prova da culpa, atento o disposto nos artigos 483. e 487. do Código Civil (11). Com efeito, cabe ao lesado, numa ação de responsabilidade civil extracontratual, provar a ilicitude do facto, a existência de um dano, o nexo de causalidade entre defeito e dano e, ainda, a culpa do produtor - quanto a esta, a prova revela-se diabólica para o lesado, porquanto este não detém os conhecimentos científicos e técnicos necessários para detetar o defeito e demonstrar que este procede de culpa do produtor, a que acresce o "caráter estatisticamente inevitável de certos acidentes e falhas técnicas que escapam ao mais elevado grau de diligência do homem e de simples erros humanos (...)" (10), independentes de qualquer culpa, revelando impossível a prova desta pelo lesado.

Todos estes argumentos conduziram ao reconhecimento da necessidade de responsabilizar diretamente o produtor, fazendo-o responder pelos danos causados pelos produtos defeituosos que coloca no mercado - e a cuja responsabilidade se eximira por via da cisão entre a produção e a comercialização dos seus produtos -, tutelando igualmente de forma efetiva todas as eventuais vítimas de danos causados por defeito do produto.

É nesse contexto que surge a Diretiva $n . \stackrel{0}{8}$ 85/374/CEE, do Conselho, de 25 de julho de 1985 (9), relativa à aproximação das disposições legislativas, regulamentares e administrativas dos Estados-membros em matéria de responsabilidade decorrente dos produtos defeituosos transposta para o nosso ordenamento jurídico através do DL n.ํ383/89, de 06 de Novembro (8), o qual analisaremos já em seguida.

\section{Metodologia}

Foi realizada análise bibliográfica sobre este tema, para indagar sobre as dificuldades que se erigem com (in)suficiências do regime legal em vigor (8), quando em causa esteja um medicamento-produto.

\section{Resultados e discussão}

Resulta do estudo levado a cabo que, muito embora o regime legal em vigor se revele adequado à generalidade dos produtos, o mesmo já não se pode afirmar quando em causa esteja um produto-medicamento em relação a alguns aspetos de regime, atentas as suas 
características próprias e a interação com o corpo humano que de imediato se estabelece. À imagem do que sucedeu em outros ordenamentos jurídicos europeus, poderia equacionar-se legislar especificamente sobre a responsabilidade civil decorrente de danos causados por medicamentos, como é o caso da Alemanha, ou consagrar algumas diferenças de regime quando em causa esteja um medicamento, como sucedeu em Espanha.

\section{O Decreto-Lei n. $383 / 89$, de 06 de novembro}

Consagra o artigo $1 . .0$ desse decreto que o produtor é responsável, independentemente de culpa, pelos danos causados por defeitos dos produtos que põe em circulação (8) resultando assim inequívoca a responsabilidade objetiva do produtor, cabendo ao lesado a alegação e prova do defeito do produto, do dano e do nexo de causalidade entre defeito e dano.

Considerado pela Diretiva Comunitária (9) o único meio de resolver de modo adequado o problema, atenta a crescente tecnicidade e complexidade dos processos produtivos, entendeu-se que a responsabilidade objetiva viria assim assegurar uma proteção adequada e eficaz ao consumidor, induzindo o produtor a adotar todas as medidas que se afigurem necessárias em ordem à máxima segurança dos produtos que coloca no mercado, incentivando-o a investir na investigação a fim de reduzir o risco de comercialização de um produto defeituoso, maxime, de eliminar definitivamente esse mesmo risco, impondo, assim uma obrigação de segurança a cargo do produtor.

\section{Noção de produtor}

Para efeitos de responsabilidade objetiva por produtos defeituosos, considera o artigo 2. 9 do DL n. $³ 83 / 89$ como sendo produtor o fabricante do produto acabado, de uma parte componente ou de matéria prima, e ainda quem se apresente como tal pela aposição no produto do seu nome, marca ou outro sinal distintivo ( $n . \stackrel{0}{1}$ ), e ainda, aquele que, na Comunidade Económica Europeia e no exercício da sua atividade comercial, importe do exterior da mesma produtos para venda, aluguer, locação financeira ou outra qualquer forma de distribuição ou qualquer fornecedor de produto cujo produtor comunitário ou importador não esteja identificado, salvo se, notificado por escrito, comunicar ao lesado no prazo de três meses, igualmente por escrito, a identidade de um ou outro, ou a de algum fornecedor precedente (8). 
Dessa definição ampla de produtor para efeitos de aplicação do mencionado DL, podemos destrinçar o conceito de produtor real, produtor aparente ou ainda de produtor presumido.

Por produtor real entende-se o realizador do produto, o seu fabricante, seja do produto acabado, de uma parte componente ou de matéria prima (1.a parte do n.ำ 1 do artigo 2.ํ) (8), entendendo-se como parte componente aquela que se destina à incorporação e constituição do produto final, e matéria prima como sendo os materiais e as substâncias destinados à produção de produtos finais e/ou de partes componentes.

Considera-se também produtor quem se apresente como tal pela aposição no produto do seu nome, marca ou outro sinal distintivo, o denominado produtor aparente $(4,10)$. Com efeito, não raras vezes, são difundidos no mercado produtos aos quais são apostos sinais distintivos de determinada pessoa, humana e/ou jurídica, quando na realidade este é produzido por outrem, segundo as suas instruções, criando face ao consumidor a aparência de que se trata de um produto próprio - falamos, a este propósito, dos grandes distribuidores, grossistas, cadeias comerciais, mas também daquele "que encarrega outra empresa ou mesmo uma sociedade - uma "sociedade filha" - de produzir um produto que ele difunde no mercado como próprio" (10) -, residindo precisamente nesta o fundamento e a justificação da responsabilidade, em ordem à proteção do lesado que tem a impressão de que aquele é o produtor, não lhe sendo exigível a identificação do produtor real. Naturalmente, se em determinado produto, para além da aposição de um sinal distintivo do comerciante, constar também a identificação do produtor real, é este que deve ser demandado, porquanto não se verifica nesta situação a dita aparência de produção. (4)

Por último, o mencionado artigo considera ainda como produtor o importador na Comunidade Europeia e o fornecedor de produto anónimo (alíneas a) e b) do n. 2 do artigo 2.ำ, respetivamente) (8) - falando-se aqui da noção de produtor presumido.

Não obstante esta densificação de conceitos, cumpre salientar, atento o disposto no artigo $6 .^{\circ}$ do DL $n .^{\circ} 383 / 89$, que se várias pessoas forem responsáveis pelos danos, é solidária a sua responsabilidade. (8)

\section{Noção de produto}

Entende-se por produto qualquer coisa móvel, ainda que incorporada noutra coisa móvel ou imóvel - artigo 3.ำ do DL n. $.^{\circ} 383 / 89$ (8). Dessa noção não resultam dúvidas que de o 
medicamento, enquanto coisa móvel, é considerado como um produto para efeitos de aplicação desta legislação, abrangendo, pela sua amplitude, os medicamentos produzidos industrialmente, mas também os medicamentos manipulados.

\section{Noção de defeito}

Se o produtor responde, nos termos do n. 91 do DL n. $³ 83 / 89$ (8), independentemente de culpa, pelos danos causados por defeitos dos produtos que coloca em circulação, importa dilucidar quando é que se considera um produto defeituoso.

Nesse sentido, estabelece o artigo 4.ำ n. 1 que um produto é defeituoso quando não oferece a segurança com que legitimamente se pode contar, tendo em atenção todas as circunstâncias, designadamente a sua apresentação, a utilização que dele razoavelmente possa ser feita e o momento da sua entrada em circulação (8). A pedra de toque para a consideração de um produto como defeituoso deixa assim de repousar na inaptidão ou inidoneidade deste para a realização do fim a que se destina - e que conforma o regime da venda de coisas defeituosas constante do Código Civil (11) - para assentar na segurança - rectius, na falta dela - do produto em questão, como conceito mais abrangente, desencadeadora da responsabilidade do produtor.

Como salientámos neste texto, não se exige que o produto ofereça uma segurança absoluta, mas tão-somente aquela com que legitimamente se possa contar, avaliada objetivamente - razão pela qual, na valoração do caráter defeituoso do produto, se deve atender

[...] não às expetativas subjetivas do lesado, à segurança com que ele pessoalmente contava, mas às expetativas objetivas 'do público em geral', isto é, à segurança esperada e tida por normal nas concepções do tráfico do respectivo sector de consumo, v.g., de adultos, de menores, de deficientes, etc. (10)

Para tanto, o DL n. $383 / 89$ (8) consagrou algumas das circunstâncias a que deve atender o julgador, designadamente, a apresentação do produto - v.g., pela adequação ou inadequação das informações que acompanham o produto, bem como o que se refere às instruções de utilização -, a utilização que dele razoavelmente possa ser feita - englobando aqui, para além da utilização específica a que o produto se destina, outras utilizações razoavelmente previsíveis que do mesmo possam ser feitas, excluindo-se apenas uma utilização abusiva do produto - e o momento da sua entrada em circulação - se o produto, nesta data, ponderadas todas as 
circunstâncias, oferecia a segurança com que legitimamente se pode contar, não poderá ser considerado defeituoso.

Em suma,

[...] se um produto não é defeituoso porque oferece um bom nível de segurança conforme às legítimas expectativas do público ou se é defeituoso porque comporta um grau de insegurança com que legitimamente não se pode contar, só o juiz o pode determinar, tendo em atenção a peculiaridade do produto em causa e todas as circunstâncias do caso concreto. (10) (grifo nosso)

E aqui, concretamente no que se refere aos medicamentos, será de suma importância atender à relação benefício-risco do medicamento - pensemos no fármaco em que, apesar de acarretar a verificação de determinados efeitos secundários, os benefícios advenientes da sua utilização superam em muito o risco criado, revelando-se aquele de extrema importância na prática médica e no combate a determinadas doenças, levando a que se reconheça que tais efeitos devem ser suportados - desde que devidamente comunicados ao paciente -, e que estamos em face de um medicamento não defeituoso, enquanto este mantiver uma relação benefício-risco positiva, concretamente avaliada.

Apesar de a lei da responsabilidade do produtor (8) nada dizer, consagrando tãosomente a noção ampla de defeito do produto, a doutrina tem identificado e distinguido vários tipos de defeitos que podem recair sobre o mesmo - falamos dos defeitos de conceção, dos defeitos de fabrico, dos defeitos de informação e dos defeitos de desenvolvimento. $(4,10,12)$.

Vejamos sucintamente cada um deles.

\section{Defeito de conceção}

Estaremos perante um defeito de conceção quando este se verifica ao nível da conceção ou idealização do produto - seja, por exemplo, por força de uma fórmula de composição errada ou por lhe ser inerente um efeito secundário perigoso, seja pelo recurso a uma matéria-prima de má qualidade ou ainda pela utilização de técnicas de produção ou controlo de qualidade impróprias. $(4,10,12)$

Porque existentes logo na fase inicial de preparação da produção, estes defeitos acabam por figurar em todos os produtos da série fabricada, sendo responsáveis, em consequência, pela materialização de danos em série. 
No que se refere aos medicamentos, estes apresentarão um defeito de conceção, principalmente, por via da "eleição de uma concreta composição química" (4), que se manifestará em todos os medicamentos produzidos com base na mesma fórmula, ou com recurso às mesmas substâncias.

\section{Defeito de fabrico}

Os defeitos de fabrico surgem já na fase propriamente dita de produção, em execução daquela idealização, e derivam de falhas mecânicas e/ou humanas, próprias da estandardização da produção e da sua automatização (v.g., deficiente empacotamento, erro na mistura de componentes, etc.). $(4,10,12)$

Contrariamente aos defeitos de conceção, que afetam todos os produtos da série fabricada, os defeitos de fabrico recairão apenas sobre algum ou alguns exemplares de uma série regular - assim, porque os exemplares defeituosos diferem do resultado esperado pelo produtor, a sua deteção torna-se mais fácil, bastando a sua comparação com outros produtos da mesma série. (10)

\section{Defeito de informação}

Contrariamente aos defeitos de conceção ou aos defeitos de fabrico, os defeitos de informação são extrínsecos ao produto propriamente dito, em si mesmo não defeituoso (4, 10, 12). Não obstante, o produto revela-se inseguro por falta, insuficiência ou inadequação das informações, advertências ou instruções sobre a sua utilização - v.g., os efeitos secundários de um medicamento, porque conhecidos antes da comercialização do mesmo, devem figurar no folheto informativo que o acompanha.

Como evidencia Calvão da Silva (10), as advertências e instruções integram ou complementam o design, na medida em que

[...] há produtos com deficiências intrínsecas de concepção ou design, conhecidas mas inelimináveis ou incorrigíveis cientificamente - é o caso dos efeitos secundários de certos medicamentos - que são considerados legitimamente seguros se e só se acompanhados das adequadas informações e advertências. (10) (grifo nosso)

Nessa medida, o folheto informativo que acompanha o medicamento deverá, entre outros, conter os seguintes elementos, atento o disposto no artigo $106 . \stackrel{\circ}{n} . \stackrel{\circ}{3}$ do Estatuto do Medicamento (3): nome do medicamento, indicações terapêuticas, contraindicações, 
precauções de utilização adequadas, instruções de utilização - incluindo-se aqui, v.g., a posologia, o modo e via de administração, a frequência de administração, a duração do tratamento - e a descrição das reações adversas que podem surgir com a utilização normal do medicamento (alíneas a), c), d), e) e g), respetivamente). Note-se que não basta a mera inclusão de todas essas informações - seja no domínio dos medicamentos, seja no domínio dos produtos em geral -, antes se exigindo a sua apresentação de forma clara, explícita e sucinta, com vista ao cabal esclarecimento da pessoa a quem se destina o produto/medicamento. Nesse sentido, estabelece o artigo 107. do Estatuto do Medicamento (3) que a inscrição dessas informações seja redigida em língua portuguesa, em termos indeléveis, facilmente legíveis, claros, compreensíveis e fáceis de utilizar para o doente (3).

Em suma, apesar de em si mesmo não se apresentar como defeituoso - porque devidamente concebido e fabricado - o produto poderá configurar-se como defeituoso quando não seja acompanhado das adequadas informações, advertências e instruções de utilização, porque e na medida em que não apresenta a segurança com que legitimamente se pode contar.

No entanto, não se pense que o dever de informação que impende sobre o produtor cessa a partir do momento da sua colocação no mercado. Com efeito, sobre este impende o dever de observar e vigiar continuamente os seus produtos, mesmo após aquele momento obrigação de vigilância post-marketing - tanto mais que essa monitorização poderá permitir a deteção de imperfeições anteriormente não conhecidas, nem cognoscíveis, induzindo-o a tomar todas as precauções, nomeadamente, pela imediata comunicação aos consumidores dos riscos em que incorrem ou até a imediata retirada do produto do mercado, sob pena de vir a ser responsabilizado.

\section{Defeito de desenvolvimento}

A doutrina tem ainda distinguido um quarto tipo de defeito, o denominado defeito de desenvolvimento $(4,10,12)$. Consubstanciam esse tipo de defeito aqueles que são incognoscíveis e indetetáveis perante o estado da ciência e da técnica no momento da colocação do produto no mercado. Mas, sobre esses, referir-nos-emos, infra, quando abordarmos as causas de exclusão da responsabilidade, em particular, a causa de exclusão da responsabilidade por riscos de desenvolvimento. 


\section{Danos ressarcíveis}

Pressuposto da responsabilidade civil do produtor é a existência de um dano, nos termos do artigo 1. do DL n. $\stackrel{\circ}{383 / 89}(8)$.

Conjugando esse preceito com o artigo 8. do mesmo diploma, serão ressarcíveis os danos resultantes de morte ou lesão pessoal e os danos em coisa diversa do produto defeituoso, desde que seja normalmente destinada ao uso ou consumo privado e o lesado lhe tenha dado principalmente esse destino.

Naturalmente que, no âmbito da responsabilidade do laboratório produtor por medicamentos defeituosos, assumem maior relevância os danos resultantes de morte ou lesão pessoal. Assim, serão ressarcíveis quer os danos patrimoniais - suscetíveis de avaliação pecuniária que resultam da lesão do bem vida ou integridade pessoal, sejam os danos emergentes, v.g., as despesas médicas, de hospitalização, de reabilitação, sejam os lucros cessantes, incluindo-se aqui os salários e/ou benefícios que deixaram de ser recebidos por força de incapacidade, temporária ou permanente, para o trabalho -, quer os danos não patrimoniais que, pela sua gravidade, mereçam a tutela do direito, sendo que o montante da compensação deverá ser fixado equitativamente pelo tribunal, atento o disposto no artigo 496. do Código Civil (11).

\section{Causas de exclusão da responsabilidade}

Considerando que uma justa repartição dos riscos entre o lesado e o produtor implica que esse último se possa eximir da responsabilidade se provar a existência de determinados factos que o isentem, a Diretiva $n . .95 / 374 /$ CEE (9) consagrou, no seu artigo 7., um conjunto de causas de exclusão da responsabilidade, transpostas para o nosso ordenamento jurídico e previstas no artigo 5. do DL n. $.938 / 89$ (8), consagrando-se uma responsabilidade objetiva limitada ao invés de uma responsabilidade absoluta.

Assim, desde logo, o produtor poderá afastar a sua responsabilidade se provar que não pôs o produto em circulação (alínea a) do artigo 5.ำ do DL n.ํ 383/89) - considerando-se a colocação em circulação do produto o momento em que aquele o lança livre, voluntária e conscientemente no tráfico para comercialização, o produtor poderá excluir a sua responsabilidade v.g., se lograr provar que este lhe foi furtado ou roubado. (8)

Depois, estabelece a alínea b) do artigo 5. que o produtor não é responsável se provar que, tendo em conta as circunstâncias, se pode razoavelmente admitir a inexistência do defeito 
no momento da entrada do produto em circulação. Tem-se aqui em vista aquelas situações em que, por exemplo, um mau acondicionamento por parte de um qualquer distribuidor torna 0 produto defeituoso, sem que o defeito possa ser imputado ao produtor. Quer isto dizer que a lei parte de uma presunção, a de que o defeito existente teve origem no processo produtivo facultando ao produtor a possibilidade de excluir a sua responsabilidade se lograr demonstrar ser plausível ou razoável a inexistência do defeito no momento da sua colocação no mercado. (8)

Por seu turno, estabelece a alínea c) que o produtor não é responsável se provar que não fabricou o produto para venda ou qualquer outra forma de distribuição com um objetivo económico, nem o produziu ou distribuiu no âmbito da sua atividade profissional, pressupostos estes de verificação cumulativa. (8)

Nos termos da alínea d), o produtor não é responsável se provar que o defeito é devido à conformidade do produto com normas imperativas estabelecidas pelas autoridades públicas. Assim, não bastará ao produtor a demonstração da conformidade com as normas imperativas, devendo este provar o nexo de causalidade entre o defeito de que padece o produto e a conformidade à norma imperativa, tem que provar que o conteúdo obrigatório da norma é que originou o defeito do produto. $(8,10)$

A alínea e) do artigo 5. do DL n. ${ }^{\circ} 383 / 89$ consagrou a denominada causa de exclusão por riscos de desenvolvimento - assim, o produtor não é responsável se provar "que o estado dos conhecimentos científicos e técnicos, no momento em que pôs o produto em circulação, não permitia detetar a existência do defeito" -, mas sobre essa referir-nos-emos mais desenvolvidamente infra. (8)

Por último, consagra a alínea f) do artigo 5. que o produtor não é responsável se provar que, no caso de parte componente, o defeito é imputável à conceção do produto em que foi incorporada ou às instruções dadas pelo fabricante do mesmo. (8)

Consoante o tipo de produto que esteja em causa, é natural que uma ou outra causa de exclusão da responsabilidade assuma maior relevância do que as demais. Concretamente no que se refere ao medicamento-produto e, bem assim, aos laboratórios farmacêuticos enquanto produtores, assumem especial relevância as causas de exclusão da responsabilidade constantes das alíneas a) não colocação do produto em circulação, b) inexistência do defeito à data da colocação em circulação e e) riscos de desenvolvimento. 
Em particular: a causa de exclusão da responsabilidade por riscos de desenvolvimento

O produtor não é responsável se provar "que o estado dos conhecimentos científicos e técnicos, no momento em que pôs o produto em circulação, não permitia detetar a existência do defeito" - alínea e) do artigo 5. do DL n.ํ 383/89 (8). Equivale isso a dizer que o produtor não é responsável por riscos de desenvolvimento.

Esse trecho do decreto-lei, que corresponde à transposição para o nosso ordenamento jurídico do artigo 7.ำ alínea e) da Diretiva n. 85/374/CEE, talvez tenha sido o mais problemático aquando da sua redação e consequente aprovação. Daí que a solução tenha passado por consagrar aqueles riscos como uma causa de exclusão da responsabilidade do produtor, não deixando de admitir, contudo, que essa possibilidade pode ser considerada em determinados Estados-membros como uma restrição injustificada da proteção dos consumidores (9), possibilitando, por essa mesma razão, ao abrigo do artigo $15 . \stackrel{\circ}{n} \mathrm{n} . \stackrel{\circ}{1}$, alínea b) da Diretiva, que os Estados-membros, possam optar por manter ou prever na sua legislação que o produtor é responsável mesmo se provar que o estado dos conhecimentos científicos e técnicos no momento da colocação do produto em circulação não lhe permitia detetar a existência do defeito - não foi o caso de Portugal. (10)

A primeira grande questão que se coloca é a de saber o que deve se entender por estado dos conhecimentos científicos e técnicos? Tem-se aduzido que o critério previsto na lei é um critério objetivo, isto é, requer-se a impossibilidade absoluta e objetiva de detetar a existência do defeito, "crucial e decisivo é a incognoscibilidade do defeito e periculosidade do produto segundo o estado geral da arte, o estado planetário dos conhecimentos científicos e técnicos, no sector" (10).

Assim compreendido, e reconhecendo ab initio que a consagração dessa causa de exclusão da responsabilidade teve em vista, a par da previsão de um prazo de prescrição e de caducidade, não onerar demasiado a posição do produtor, optando pela consagração de uma responsabilidade objetiva limitada, ao invés de uma responsabilidade absoluta, somos levados à segunda grande questão: considerando os interesses aqui presentes, particularmente quando em causa esteja um medicamento defeituoso, não terá essa limitação da responsabilidade do produtor frustrado a intencionalidade subjacente a esse regime, a de tutelar adequadamente a pessoa lesada? Importa, para tanto, aduzir dos argumentos que têm sido erigidos a favor e 
contra a consagração de uma tal causa de exclusão da responsabilidade (4), para respondermos àquela questão.

Desde logo, a favor da consagração dessa causa de exclusão, invoca-se tradicionalmente o excesso de penalização do produtor ao responsabilizá-lo por defeitos que eram indetetáveis aquando da colocação do produto no mercado. Depois, porque a responsabilização por riscos de desenvolvimento dificultaria a contratação de seguros, nomeadamente, pelo aumento dos prémios que, sendo repercutidos no preço dos produtos, conduziriam a um aumento do preço dos mesmos. Da conjugação desses dois argumentos resultaria um desincentivo à investigação e desenvolvimento de produtos de alto risco, desacelerando a inovação tecnológica.

No sentido contrário, isto é, contra a consagração dessa causa de exclusão e, portanto, propugnando pela responsabilização dos produtores, tem-se invocado os benefícios advenientes da colocação de um produto no mercado, a implicar a consequente assunção dos riscos que daí derivam por parte daqueles. Depois, tem-se entendido que a admissão dessa causa de exclusão constitui um obstáculo à realização da responsabilidade objetiva, com óbvio prejuízo para o lesado (4), admitindo-se a exoneração da responsabilidade precisamente numa área em que os riscos e eventuais danos sobrevindos são mais sensíveis (4). Também nesse sentido é frequente o argumento trazido à colação de que a responsabilidade por riscos de desenvolvimento incentivaria a investigação antes da colocação do produto no mercado, com as vantagens daí advenientes para a segurança dos produtos. (4)

Ponderados os argumentos que têm sido esgrimidos num e noutro sentido, estamos em condições de afirmar o seguinte: prever que um produtor se possa exonerar de responsabilidade, provando, para o efeito, que o estado dos conhecimentos científicos e técnicos não permitia detetar a existência do defeito, é frustrar precisamente aquilo que se quis acautelar, leia-se, é frustrar a tutela eficaz do lesado. Senão vejamos: uma coisa é a existência do defeito, outra é a sua detetabilidade; ainda que seja indetetável, o defeito existe - e existe no momento em que o produto é colocado em circulação no mercado. Assim, se em virtude desse defeito advêm danos, as mais das vezes danos em massa, graves e irreversíveis, não nos parece aceitável a sua não ressarcibilidade, verificados que estão os pressupostos para que exista responsabilidade civil do produtor.

Além do que fica dito, somos levados a questionar se, no que concerne à indústria farmacêutica - e tendo presentes as limitações inerentes aos ensaios clínicos prévios à 
comercialização de um determinado medicamento -, os defeitos serão verdadeiramente incognoscíveis e indetetáveis aquando da sua colocação no mercado, ou simplesmente não foram detetados por força daquelas mesmas limitações?

\section{Dificuldades de prova em matéria de nexo de causalidade}

Para que determinada pretensão seja procedente com base no regime da responsabilidade objetiva do produtor, deve o lesado fazer prova dos factos constitutivos do direito alegado, a saber, (i) a existência de um dano; (ii) o defeito do produto; e (iii) o nexo de causalidade entre defeito e dano, atento o disposto no artigo $4 .^{\circ}$ da Diretiva $n . \circ 85 / 374$ (9) e o artigo 342.ำ do Código Civil português. (11)

Tendo já feito alusão ao defeito do produto e aos danos ressarcíveis, resta-nos atentar no pressuposto do nexo de causalidade entre o defeito do produto e o dano sobrevindo. Não dispondo o DL n. 383/89 (8) de norma especial relativamente a esse pressuposto, terá aqui plena aplicação o artigo 563. do Código Civil (11), segundo o qual a obrigação de indemnização só existe em relação aos danos que o lesado provavelmente não teria sofrido se não fosse a lesão.

Este é talvez o pressuposto que mais dificuldades levanta para o lesado, dificuldades essas que se agigantam quando em causa esteja um medicamento defeituoso. E porquê? Porque, por um lado, os efeitos adversos provocados por um determinado medicamento têm de característico só se manifestarem decorrido um amplo lapso de tempo desde o momento da sua administração - denominado período de latência -, levando a que não ressalte de imediato que a verificação desses efeitos se deve a um qualquer defeito do fármaco. Por outro lado, a reação eventualmente sofrida pode não derivar causa-efeito da toma do medicamento e, portanto, de um seu defeito, mas antes de uma predisposição da pessoa lesada, eventualmente da evolução do seu estado de saúde - se padecesse já de uma qualquer patologia - ou, ainda, de uma qualquer reação medicamentosa em virtude do tratamento simultâneo com vários medicamentos e em que a reação adversa advém mais da sua combinação, e menos de um defeito de um dos medicamentos administrados.

Para além de todas as dificuldades apontadas e que derivam, sobretudo, da especificidade do medicamento enquanto produto, particularmente problemático se tem revelado, não raras vezes, a identificação do concreto laboratório produtor do medicamento defeituoso, não obstante a noção ampla consagrada entre nós no artigo $2 . .^{\circ}$ do DL n.ำ383/89 
(8), quando em causa estão medicamentos genéricos, produzidos e comercializados por diferentes laboratórios, sob fórmula idêntica, por via de um licensing agreement, a que acresce o facto de, geralmente, a pessoa lesada consumir o fármaco comercializado pelos diferentes produtores v.g., porque o mesmo é distribuído pelos vários laboratórios na farmácia onde habitualmente os adquire. Assim,

[...] se formos inflexíveis na observância da regra de que cabe ao lesado demonstrar quem é o agente concreto causador dos danos, dentro do princípio de que cada um responde apenas pelos prejuízos que provoca, a responsabilidade do produtor ou produtores demandados será quase sempre recusada neste tipo de casos por falta de prova da identificação do causador real e específico dos danos [...] (10).

Exemplo paradigmático do que acaba de ser dito é o caso DES, a que fizemos referência. O dietilestilbestrol foi um medicamento genérico colocado no mercado dos Estados-Unidos da América (EUA) na década de 40 do século passado - e também comercializado na Europa -, o qual passou a ser utilizado, sobretudo a partir de 1948, com o objetivo de prevenir o aborto espontâneo. Só em 1971, com a publicação de um estado de caso-controlo elaborado por HERBST (1), é que se estabeleceu a relação causal entre a toma do fármaco e os seus efeitos nocivos, concretamente, o desenvolvimento de adenocarcinoma vaginal nas filhas das mulheres que tomaram esse medicamento (comummente designadas de DES daughters), expostas ao mesmo in utero, porquanto o cancro só se manifestou entre 12 a 25 anos depois da sua administração às progenitoras. Esse genérico era, na altura, produzido por cerca de 200 laboratórios, tendo-se revelado difícil - senão mesmo impossível - identificar o concreto produtor do medicamento consumido, gerador de danos por via de defeito que the era inerente. (4)

"Reconhecida e assumida a dificuldade-impossibilidade de identificação do produtor específico causador do dano concreto, há que remediar a situação com uma solução que socorra o lesado no estado de necessidade de prova em que se encontra" (13). Nos EUA, a mencionada solução foi alcançada por via da teoria da market share liability (MSL), naquele que é considerado o verdadeiro leading case em matéria de responsabilidade civil de laboratórios produtores de medicamentos - o caso Sindell v. Abbot Laboratories. Aquela era uma das DES daughters que, não logrando identificar o concreto produtor do fármaco, propôs uma ação contra vários laboratórios produtores de DES - in casu, cinco dos duzentos produtores que, no seu conjunto, representavam $90 \%$ do mercado. O Supremo Tribunal da Califórnia responsabilizou 
os vários produtores demandados, na proporção das respetivas quotas de mercado (4). Ainda que, como veremos, essa teoria venha sendo rejeitada nos vários ordenamentos jurídicos europeus, entre os quais se inclui Portugal $(10,13,14)$, não pode deixar-se de enfatizar o objetivo com que a mesma foi erigida, isto é, o de facilitar à vítima a identificação do concreto responsável pelos danos causados, assente na consideração de que entre ela e os produtores de um produto defeituoso, devem ser esses últimos a suportar os danos causados.

Apesar da intencionalidade subjacente a essa teoria, a mesma não deixa de ser isenta de críticas $(4,10,13,14)$. Desde logo, porque responsabilizando os vários produtores em função da sua quota de mercado, leva, por um lado, a que a responsabilidade não seja solidária, fazendo recair sobre o lesado o risco de algum dos produtores se vir a tornar insolvente ou simplesmente desaparecer do mercado, bem como o risco de um ou algum dos produtores conseguir demonstrar que não produziu ou não distribuiu o produto causador do dano e, por outro, porque respondendo os vários produtores em função da sua quota de mercado, incentivase a vítima a demandar todos os produtores do medicamento com vista à reparação integral do seu dano, quando, na verdade, "o círculo dos possíveis responsáveis - aqueles que criaram o risco abstracto susceptível de se ter materializado no caso concreto -" se limita a alguns daqueles produtores $(4,10,13,14)$.

A teoria da market share liability tem sido rejeitada nos ordenamentos jurídicos europeus $(4,10,13,14)$. Ao invés, o problema da dificuldade/impossibilidade de identificação do concreto laboratório produtor tem sido resolvido em sede de causalidade alternativa. Para tanto, muito contribuiu a decisão do Supremo Tribunal Holandês datada de 09 de outubro de 1992, onde expressamente se rejeitou a aplicação da teoria da MSL, pugnando pela desnecessidade da sua aplicação em casos como esses. Em causa estava uma ação proposta por seis vítimas de danos causados pelo medicamento DES contra dez produtores do mencionado fármaco, alegando, em síntese, que os dez haviam produzido e colocado em circulação o medicamento no período correspondente ao consumo pelas suas progenitoras, razão pela qual deveriam ser solidariamente responsabilizados, por aplicação do artigo 99.ำ do Livro VI com Código Civil Holandês. (4)

O Supremo Tribunal acabaria por responsabilizar solidariamente cada um dos produtores demandados, aplicando o mencionado preceito, e rejeitando a aplicação da teoria da MSL, considerando inadmissível que o risco de insolvência ou desaparecimento do mercado de um dos produtores corresse por conta das vítimas e, ainda, que a aplicação da mencionada teoria 
"exige que a vítima demande suficientes produtores para que possam representar uma significante quota do mercado do produto em questão" (4) (10).

Entre nós, considera Calvão da Silva (10) que, nesses casos, será suficiente - mas necessário - a prova da razoável probabilidade de o laboratório demandado ser o responsável no caso em concreto. Debruçando-se sobre o caso DES, considera o autor que

[...] se o risco abstracto criado por cada produtor de DES é susceptível de constituir a causa real e concreta dos danos, não parece conforme a qualquer razão prática e jurídica que a vítima não o possa imputar aos fabricantes pelo simples facto de que o produtor não possa ser individualizado. (10) (13)

Assim, aderindo à formulação negativa da causalidade adequada, entende o autor que bastará à vítima provar que a atuação dos produtores é conditio sine qua non, presumindo-se causa adequada do dano, suscetível de constituir a causa real e concreta dos danos - recaindo sobre aqueles o ónus de demonstrar que não foi o medicamento por si produzido e comercializado o causador do dano.

A responsabilidade estabelecida nestes termos seria, de acordo com o artigo 497.. do Código Civil, solidária, respondendo cada um dos produtores pela prestação integral (artigo 512. do mesmo diploma). (11)

\section{Prescrição}

Estabelece o artigo 11. do DL n. $.383 / 89$ (8) que o direito ao ressarcimento prescreve no prazo de três anos a contar da data em que o lesado teve ou deveria ter tido conhecimento do dano, do defeito e da identidade do produtor. A menção feita a esses três elementos na parte final do artigo é deveras importante, pois que só a partir deste momento é que o lesado se encontra verdadeiramente na condição de poder intentar uma ação

Com efeito, não raras vezes, o dano exterioriza-se posteriormente à sua verificação - só se tornando cognoscível pelo lesado a partir desse momento - ou, ainda, pode o mesmo ser insignificante de início, e só posteriormente assumir relevância tal que justifique a proposição da ação - circunstâncias que ocorrem com particular incidência no domínio dos medicamentos.

Também nesse domínio serão aplicáveis as disposições que regulam a suspensão ou a interrupção do prazo de prescrição, constantes do Código Civil (artigos 318. a 327. do Código Civil) (11), atento o disposto no artigo 10./2 da Diretiva. (9) 


\section{Caducidade}

Para além da previsão de causas de exclusão da responsabilidade e do estabelecimento de um prazo de prescrição, também a fixação de um prazo de caducidade teve em vista não onerar demasiado a posição de produtor, por se considerar que a sua eventual responsabilização não deveria ser ilimitada no tempo.

Assim, prevê o artigo 12.ำ do DL ก.. 383/89 que, decorridos 10 anos sobre a data em que o produtor pôs em circulação o produto causador do dano, caduca o direito ao ressarcimento, salvo se estiver pendente ação intentada pelo lesado. (8)

Temos que o prazo de 10 anos se compreenderá quando em causa estejam produtos em que a vida útil do mesmo corresponde sensivelmente àquele - pensemos, v.g., nos eletrodomésticos. No entanto, tal prazo revela-se manifestamente insuficiente quando estejamos perante um medicamento defeituoso, principalmente se tivermos em linha de conta o caráter dito latente de certos efeitos, levando a que os danos sobrevindos sejam, não raras vezes, de manifestação muito tardia - nesse sentido, recordemos o caso DES, em que as consequências da toma daquele fármaco só se revelaram entre 12 a 25 anos depois da sua administração, e que ainda hoje continuam a manifestar-se, bem como no caso da talidomida precludindo, assim, a possibilidade de obter uma indenização com base no regime da responsabilidade civil do produtor.

Decorrido o prazo de 10 anos, e porque o regime da responsabilidade do produtor não afasta a responsabilidade decorrente de outras disposições legais (artigo 13..) (8), restará ao lesado socorrer-se das regras gerais da responsabilidade civil, com todas as dificuldades que Ihe são inerentes, como vimos, mormente, a exigência de prova da culpa, diabólica para 0 lesado.

\section{Conclusão}

Iniciámos o presente texto com a constatação de que a segurança dos medicamentos não é absoluta. Dissemos também que tal não é exigível - preponderante é que a relação benefício-risco de um concreto medicamento seja favorável -, mas talvez nesse domínio em particular se deva almejar o quase absoluto.

Sem prescindir, é igualmente imperativo, face à evolução dos conhecimentos científicotécnicos, com a natural consequência de surgirem mais medicamentos, cada vez mais complexos, com propriedades cada vez mais abrangentes e intervenientes, que a sua 
monitorização seja máxima e constante. Para tanto, impor-se-á continuar com o trabalho desenvolvido em ordem ao incremento da atividade de farmacovigilância, atividade essa que será garante da prevenção, mas sobretudo, garante do não surgimento de novas catástrofes como as já analisadas. Nesse sentido, é de salientar o aumento verificado no número de notificações espontâneas de RAM - e, de entre estas, o aumento do número de notificações de reações adversas graves e inesperadas. Tal aumento é expressivo do maior conhecimento e consciência quanto à preponderância daquela atividade, mas, simultaneamente, a evidência de que tais reações ocorrem, a que acresce o facto de constituírem a segunda maior causa de verificação de um evento adverso em internamento hospitalar, em Portugal, e de afetarem cerca de $7 \%$ da população em geral.

O que acaba de ser dito é a evidência de que as reações a medicamentos constituem, ainda hoje, um problema de saúde pública, o mesmo problema que esteve em parte na origem da Diretiva em matéria de responsabilidade por produtos defeituosos e, em consequência, do diploma de transposição - entre nós, o DL n. 383/89 (8) -, na senda da products liability, originariamente surgida nos EUA, e que rapidamente se espraiou ao continente europeu, não fosse o desastre da talidomida, ocorrido na Alemanha. Da análise daquele diploma, também levada a cabo, ressalta a inadequação de certos aspetos de regime quando em causa esteja 0 produto-medicamento, a saber, a causa de exclusão da responsabilidade por riscos de desenvolvimento - parecendo-nos mais consentânea a ideia da sua consagração em geral, mas excluindo a possibilidade da sua invocação quando em causa esteja um medicamento - e a insuficiência do prazo de prescrição de 10 anos constante do mesmo diploma legislativo, considerada a manifestação tardia de certos efeitos, que não raras vezes se verifica, à qual se associa, v.g., a dificuldade de associação de uma determinada reação à toma de um medicamento defeituoso, nomeadamente, pela similitude com reações que derivam da evolução do estado de saúde da pessoa lesada.

A par dessas insuficiências, ainda que tenha sido dado o passo no sentido da objetivação da responsabilidade do produtor, como via natural para a eficaz proteção da pessoa lesada, nem por isso essa última se deixa de deparar com inúmeras dificuldades, atenta a tecnicidade inerente a esse tipo de produto e em relação ao qual os eventuais lesados se afiguram totalmente leigos, levando a questionar se aquela proteção se encontra efetivamente concretizada - mormente pela generalização da produção e comercialização de medicamentos genéricos, produzidos por uma multiplicidade de laboratórios, levando a que se revele 
difícil/impossível a identificação do concreto laboratório produtor do concreto medicamento defeituoso, gerador de danos na esfera físico-psíquica da pessoa lesada. Ora, não existindo no nosso ordenamento jurídico norma idêntica às dos ordenamentos jurídicos holandês e alemão, a consagrar expressamente a solidariedade dos vários laboratórios, contanto que seja feita prova de que pelo menos uma das condutas se revela apta a produzir o dano verificado, sem que consiga provar-se qual delas realmente causou o dano, e ainda que o sentido de justiça nos revele de imediato a solidariedade da responsabilidade como a melhor solução, sempre dependerá da prova produzida em juízo e, bem assim, do labor da jurisprudência portuguesa, já que aplaudida pela doutrina.

Aqui chegados, da constatação efetuada supra de que se verifica um aumento do número de notificações de reações adversas graves e inesperadas e, por outro lado, da inexistência no nosso ordenamento jurídico de decisões atinentes à responsabilidade civil do laboratório produtor de um determinado medicamento, estamos em condições de afirmar que existem danos causados por medicamentos defeituosos que não são ressarcidos, seja porque não notificados, seja porque não demandados os seus produtores. Ora, aqui, à imagem da evolução verificada no exercício da medicina, mais do que uma lógica de responsabilização, devem imperar os princípios da transparência, da solidariedade existencial e do ressarcimento do dano injustificado. Assim, por um lado, evita-se a repetição desnecessária de eventos adversos, só possível através do estudo dos já verificados e do aperfeiçoamento da atividade em saúde, v.g., pelo aperfeiçoamento de protocolos clínicos, pela criação de bases de dados de reações adversas, entre outras medidas e, por outro lado, ressarce-se aqueles que acabam lesados por uma indústria que a todos aproveita. Além das razões aduzidas, porque os medicamentos estão sujeitos, durante todo o seu ciclo de vida, ao controlo de uma entidade administrativa - entre nós, o Infarmed -, somos levados a considerar que esta deve ter um papel ativo também - mas sobretudo - quando do consumo de um determinado medicamento advenha um dano, consequência de um qualquer defeito do mesmo, mas também, quando se verifica um dano desproporcionado, com a certeza de que teve origem medicamentosa, sem que se consiga estabelecer a causalidade com um concreto defeito do medicamento em questão.

Seja por via da revisão do regime de responsabilidade por produtos defeituosos em geral - a qual se começa já a desenhar ao nível das instituições europeias -, seja excetuando a aplicação de certos preceitos quando em causa esteja um medicamento defeituoso, para quando uma mudança de paradigma? 


\section{Referências}

1. Herbst AL, Poskanzer DC. Adenocarcinoma of the vagina. Association of maternal stilbestrol therapy with tumor appearance in young women. N Engl J Med, 1971, 284(15), 878-81. Disponível em:

http://docs.bvsalud.org/biblioref/2019/12/1046556/femina-2019-4711-831-833.pdf [acesso em 11.fev.2020].

2. Raposo VL. Danos Causados por Medicamentos: Enquadramento Jurídico à Luz do Ordenamento Europeu. Portugal: Edições Almedina; 2018.

3. Portugal. Decreto Lei n.. $176 / 2006$, de 30 de agosto. Estabelece o Regime Jurídico dos Medicamentos de Uso Humano. Disponível em:

http://www.pgdlisboa.pt/leis/lei_mostra_articulado.php?nid=1884\&tabela=leis [Acesso em 11.fev.2020]

4. Silveira DM. Responsabilidade Civil por Danos Causados por Medicamentos Defeituosos. Coimbra: Coimbra Editora; 2010.

5. Batel-Marques F, Mendes D, Alves C, Penedones A, Dias P, Martins A et al. Farmacovigilância em Portugal: Atividade da Unidade Regional do Centro. Ata Médica Portuguesa, mar.-abr., 2015: p. 222-232.

6. Ribeiro-Vaz I, Herdeiro MT, Polónia J, Figueiras A. Estratégias para aumentar a sensibilidade da Farmacovigilância em Portugal. Revista de Saúde Pública. 2011: p. 129135.

7. Romão N. Farmacovigilância - Qual a perceção da Indústria Farmacêutica em relação à Farmacovigilância, 2016.

8. Portugal. Decreto Lei $n . \stackrel{0}{383 / 89}$, de 06 de novembro. Transpõe para a ordem jurídica interna a Diretiva $n . .085 / 374 / C E E$, em matéria de responsabilidade decorrente de produtos defeituosos. Disponível em:

http://www.pgdlisboa.pt/leis/lei_mostra_articulado.php?nid=729\&tabela=leis\&so_miolo= [Acesso em 11.fev.2020]

9. União Europeia. Diretiva 85/374/CEE, de 25 de julho de 1985, relativa à aproximação das disposições legislativas, regulamentares e administrativas dos Estados-membros em matéria de responsabilidade decorrente dos produtos defeituosos. Disponível em: https://eur-lex.europa.eu/legal-content/PT/TXT/?uri=CELEX\%3A31985L0374 [Acesso em 11.fev.2020]

10. Silva JC. Responsabilidade Civil do Produtor. Coimbra: Coimbra Editora; 1999.

11. Portugal. Decreto-Lei n. $.47344 / 66$, de 25 de novembro. Aprova o Código Civil e regula a sua aplicação. Disponível em:

http://www.pgdlisboa.pt/leis/lei_mostra_articulado.php?nid=775\&tabela=leis [acesso 11.fev.2020] 
12. Carla G. A responsabilidade civil médica: um problema para além da culpa. Coimbra: Coimbra Editora; 2008. p. 145-152.

13. Silva JC. Causalidade alternativa: L'arrêt DES. European Review of Private Law. 2. 1994. p. $465-469$.

14. Barbosa M. Responsabilidade por danos em massa: reflexões em torno da teoria da market-share liability. In: Estudos de Direito do Consumidor, n.. 10. 2016: p. 175-220.

Como citar este artigo:

Martins M. Danos causados por medicamentos: responsabilidade civil do produtor no âmbito da legislação portuguesa. Cadernos Ibero-Americanos de Direito Sanitário. 2020 jan./mar.; 9(1): 59-84.

http://dx.doi.org/10.17566/ciads.v9i1.607 